The Geneva Papers on Risk and Insurance, 23 (No. 89, October 1998), 506-518

\title{
Shaping the Future for the Insurance Sector
}

\author{
by Lutgart Van den Berghe*
}

\section{Some introductory remarks}

On the basis of research and trend observation, it can be argued that the insurance sector of the future will bare little resemblance to that of the past 50 years. This "revolutionary" shift is caused by many complementary structural changes. In this contribution we will try to picture some of, what we believe to be, the most fundamental strategic issues which the insurance sector is now facing and will be facing in the next decades.

\section{From local over multinational towards global competition}

In order to understand the fundamental challenges of the modern competitive environment, it is necessary to make the distinction between multinational and global competition.

\subsection{From local competition towards multinational competition}

Until the last decade, the retail business of insurance companies was mainly characterised by local competition. The industrial insurance market, on the contrary, has been faced with multinational competition for quite a long time. The internationalisation of their clientele obliged them to follow their multinational clients. Moreover, maturing and saturated home markets forced insurers, looking for higher growth potential, to expand in emerging countries. More recently, insurers working in the local retail market, are also witnessing the transition from mainly local competition towards a more multinational competition due to the creation of the European market.

* De Vlerick School of Management, University of Gent, and the Erasmus University of Rotterdam, NL. 
A typical characteristic of multinational competition is that the multinational supplier follows the rules of the host country : competition between local suppliers and foreign subsidiaries is mainly based on the local competitive rules, the local legislation and the local market characteristics. Consequently, there was little or no need for an integration between the different subsidiaries of international groups in a multinational competitive environment. As long as the performance was up to the group's standards, neither the competitive environment, nor the business calculus stimulated a great deal of coordination. Each group member developed its own strategy and marketing and only some overhead elements were coordinated in cooperation with the head office (such as the best possible financial structure).

\subsection{From multinational (competition) towards global competition}

Although there remains quite a large difference between the industrial and the retail market as well as between the banking and the insurance sector, it can be stated that the multinational competition is being increasingly replaced by European and even global competition. It is our firm belief that although the deregulation and the freedom of services within the European Union has triggered this development, the market players themselves have been the real accelerator of this globalised competition:

- competitors increasingly approach the competitive game from a global perspective;

- also the client base becomes increasingly globalised; the larger clients are more and more looking for globally integrated risk management solutions; small and mediumsized enterprises as well as a growing number of private customers will get access to the world-wide shopping around, especially through the Internet;

- the competitive struggle forces national and regional players to cope with these global competitors; this often leads to a "me-too" strategy, whereby most of the market partners realise that they need to expand their scope to stay competitive in this tough market. Consequently many opt for both national and international expansion, hereby looking for economies of scale and economies of scope to increase their competitive edge. Another feasible strategy for companies who only work the local market is to take advantage of their embedment in the local roots.

The rules of the game in a global competitive environment are quite different from those in a multinational competition : it is no longer the local market environment, the local regulation and the local players that dictate the competitive rules. In this respect the Goodyear-Michelin case is quite an interesting example (see separate box).

The major players are establishing a global strategy and marketing, exploiting their economies of scale and scope and their world-wide knowledge and reach. Global players are increasingly looking for "interactions' and "co-ordination" in order to optimize the different group members, thus following the guidelines, prescribed by management experts (Ackoff - 1994) :

"effective corporate management focuses on the interactions of its parts rather than on their actions taken separately. ...Synergy is an increase in the value of the parts of a system that derives from the interactions between the parts of a system. Such an increase in value can only occur if the parts can do something together that they can 
The famous competitive struggle between Michelin and Goodyear gives an excellent idea of the difference between multinational and global competition.

At the beginning of the seventies, Michelin - producer of tires - had a strong position in Europe, while Goodyear was especially active in the U.S. market. Michelin decided to expand internationally and started attacking the U.S. market with an aggressive marketing policy. Goodyear felt that his strong competitive position in the U.S. was being threatened by a multinational competitor, entering his market.

Two possibilities of counterattack were studied : the multinational and the global approach.

The multinational competitive strategy of Goodyear would have been to react immediately to Michelin's attack by countering the aggressive marketing approach in the U.S. by an even more aggressive marketing. Such a solution would have harmed Goodyear, because the U.S. was it main market.

The second option, namely the global competitive strategy, was chosen. Because Michelin was more vulnerable in its European home market, where Goodyear was a marginal player, they decided to attack Michelin in Europe with the same aggressive strategy used by Michelin in the US.. This global approach proved to be successful, since Michelin shifted gear to a more moderate approach in the American market.

not do alone....If the parts of a corporation do not interact, they form an aggregation, not a system.... (in the latter case) the only thing their parts have in common is their ownership... No part of a corporation can be justified unless it contributes to the value of the corporation as a whole. On the other hand, a corporation is not justified in containing a unit to which it does not add value or that would have a higher value outside the corporation than within it. The value that a unit gains by being part of a corporation derives from its interactions with other units".

The insurance intermediaries (brokers) are apparently taking the lead in this globalization trend. During the last couple of years, mergers between the major players, have considerably increased the gap with the rest of the market players. The middle market will have to reposition itself, whereas the smaller market players are increasingly looking for a shelter, either by linking themselves with a limited number of insurers, by entering into franchise networks or even by abandoning the competitive game through the sale of their business to other market players.

However, the most remarkable trend is that the major intermediaries are not only expanding within the insurance distribution, but that they are also diversifying into the direction of alternative risk management (captives, self-insurance), alternative risk financing (derivatives, risk bonds, etc.) and investment. This growth strategy can be achieved in different ways : through internal growth, mergers \& acquisitions as well as through networking. An interesting example in this respect is the collaboration between 
Marsh \& Mac and the Japanese Putnam group, a collaboration that places them in a powerful position for the battle of the future.

Insurance companies are somewhat lagging behind in this global concentration. Only a few players can really pretend to be world players, whereas the group of the middle market is still very important. These numerous groups of companies have apparently not yet decided whether they will opt for a regional or a global approach, for a niche or specialist strategy or for diversification. As will be explained further, the options are more subtle than just between specialist or full fledged financial conglomerates (point IV).

\section{The revolution in the insurance sector}

A totally new insurance sector is emerging as a result of the combined effect of supply and demand side revolutions.

\subsection{Revolution on the supply side}

1. The insurable mass and the insurance portfolio are changing drastically :

- in our part of the world, the mature market segments will become less important because they offer less favorable growth and expansion perspectives; this can be explained by a number of structural factors :

- market saturation : a stagnation of the population, a low degree of expansion of the risk base, coupled with a high insurance penetration ratio, few uninsured risks, etc.; this is e.g. the case with car and fire insurance;

- the decline of the industrial society; e.g. risks related to factory workers, to industrial production;

- the new market growth will come from different perspectives :

- the segments where the welfare state takes a step backwards; e.g. personal risks, saving and investments, employee benefits;

- the approaches that give the very demanding customer more value for his money : unbundling and rebundling of insurance products, e.g. vendor programs (in buying a full service car (or mobility) the insurance is a very important part of the complete service deal), integrated financial services (family risk management, personal financial planning), etc.;

- the business categories that will prosper in the knowledge society of the future; e.g. high tech business, telecommunication;

- the risks resulting from the higher mobility within a globalizing world; e.g. expatriates, interna-tional transportation.

2. Alternative risk handling techniques like self-insurance, captives and prevention decrease the role of traditional insurers in commercial lines of business, leaving them with the more difficult parts of the risk spectrum (catastrophic risks, risks with higher volatility and lower statistical reference bases such as business, product and environmental liability). 
Swiss Re is very successful in developing alternative risk financing instruments. Recent annual reports already show the massive growth of these new developments. An interesting in-depth analysis of some of the new risk financing techniques shows the great potential of insurance derivatives and securitization (SIGMA - 1996).

Another interesting development has been the launching of risk bonds by USAA in order to find cover against catastrophic risks. This deal was set up in June 1997, together with investment brokers Merill Lynch, Goldman Sachs and Lehman Bros.

In this respect an interesting statement was made by Latza (1997): "We believe that, in the long term, the capital market access represented by securitization of insurance risk, together with the development of hybrid products that blend traditional insurance with capital market risk-transfer devices like derivatives, will gain prominence and perhaps become the norm as risk managers adopt a more holistic view of businesses" exposures to physical and financial loss and an appropriate legal, accounting and tax regime evolves."

3. Alternative risk financing instruments (securitization, derivatives, risk bonds, etc.) create new markets and increase the insurance capacity. At the same time they attract major competitors from the financial markets (investment bankers, corporate bankers, securities firms...). The following frame sheds a light on some of the interesting recent developments in this respect.

\subsection{Revolution on the demand side}

The knowledge worker is a totally different customer than the industrial worker; he wants to be part of the game, decide what to buy, when, from whom. He has very high standards of expectation: the products have to be tailored to his specific needs and offered with great convenience. Furthermore, the price has to be competitive. It is difficult to understand this new customer because the traditional marketing tools are inadequate: the old marketing tools lead to the (false) conclusion that the customer is "schizophrenic", that he is a spoiled, unsatisfied shopper, and that the solution is an extreme broad choice of products and tarification structures (see further point IV).

\subsection{Revolution in business strategy}

The combined effects of this critical consumer, the revolution at the supply side and the global competition creates an extremely competitive market, a phenomenon that will probably last for a couple of decades. In such a volatile and complex market environment, simple solutions are no longer sufficient. According to Ackoff (1994) and Van Asseldonk (1995) there is a tendency to oversimplify the problem and the solution; neither TQM, nor BPR, Core Competence, strategic alliances, down or rightsizing, shareholders' value and corporate governance will be the ultimate answer to the threats the enterprises are facing. A more complex problem needs more complex solutions. 


\section{The modern democratic corporation}

The organisation of the business environment is - to a large extent - influenced by our view of world and by the environment the business has to operate in. The first enterprises mainly operated as machines (the mechanistic view of the enterprise), i.e. as many tasks as possible were standardised and mechanised in order to obtain profit. In a second stage the enterprise became more and more human, operating as an organism, thereby also giving attention to the interests of all stakeholders, but within the borderlines of strict control and hierarchy. In the knowledge society of the future the enterprise must be organised as a social system, i.e. a system in which people, individually and collectively, play the major part and in which they have goals of their own (Ackoff -1994). de Geus (1997) speaks in this respect of the "living corporation".

In the turbulent and chaotic global competitive environment, such a social system embedded in the knowledge society - must adopt new management principles :

- from control and 'power over' to leadership, motivation tolerance and 'power to';

- from centralisation and autocracy to democracy (the circular organisation);

- from a strict hierarchical structure towards self-managing profit centres;

- from organisation of labour and power based on either functional lines (input units), product or service lines (output units) or market lines (geographical areas, market segments) towards multi-dimensional organisations (to make flexible changes and refocusing possible without demotivating and continuous reorganizations);

- from life-time employment within strict hierarchical lines of promotion to life-time learning and continuous education within (a) learning organisation(s).

The application of these general guidelines in the insurance sector deserves some extra attention.

\section{A modern marketing philosophy and strategy for the insurers of the future}

The true needs and expectations of the modern customer are not met by the insurance policies, offered by the traditional insurance sector. Whereas the buying power and expert position of business clients have led to an improvement in the risk management services offered to them, there is still an enormous gap in the retail market between expectations and needs (at the one hand) and the product definitions (at the other hand). Inventiveness and imagination alone will not be enough to meet the customers expectations; it will take daring and persistence to develop the services of the future. The main problem will not be the technological barriers, but the inability to think in radically different paradigms about clients, services and business processes.

\subsection{From cost-led pricing to price-led costing}

The actuarial techniques, underlaying the tarification of insurance products and the a-priori supervision or self-regulation made cost-led pricing possible, whereby the market price was defined on the basis of all cost components. The changes in the regulatory environment eliminated the price bottom, laid down by the regulatory or self-regulatory bodies. In combination with the hypercompetitive market environment, insurers feel 
obliged to opt for price-led costing. Such a competitive price setting can not be successful if it is based on cost cutting strategies in parts of the production cycle (e.g. cutting commissions); it has to be based on the integrated management of the whole cost chain. In a price-led costing system with more disclosure, cross-subsidization between client and product segments and between distribution formulas is no longer feasible.

\subsection{From standard products over market segmentation towards mass-individualization}

After a period of standardised insurance products, without any tailoring at all, most insurers are now in the process of segmenting their customer base and adopting a specific marketing mix for each of the relevant segments. Combined with the move towards detailed differentiation of tariffs, this led to an explosion of the product assortment. Neither insurers, nor brokers and clients are happy about this overwhelming supply. Quite on the contrary, they are now faced with what is called a "meaning gap": although customers want to be better informed and advised on the best choice for them, they do not want to be told what to take, nor are they looking to be blinded with science or overwhelmed with too many options. The marketing challenge modern insurers are facing, is finding the right way to service their clients.

What modern marketeers are now seeing, is that the traditional segmentation techniques no longer a guaranteed success. The volatile and so-called capricious customer can only be offered tailor-made products and services at a competitive price if the corporation opts for mass-customization and preferably even mass-individualization :

- mass-customization: is directed towards customizing standard products or product modules at the end of the supply-chain (e.g. the sale of a car, a mortgage or a life insurance); since this tailoring is only done at the end of the production cycle, and the needs and wishes of customers are very diverse and change over time, this marketing philosophy leads to a labyrinth of choices and makes the buying process more complicated and expensive for all partners involved;

- mass-individualization: here the product is really individualised by involving the customer in its design and production from the very beginning (e.g. FedEX-experiment whereby the customer can follow the delivery of his package through the Internet or National Bicycle Japan which offers individualised bicycles within a short time frame at mass-prices, thanks to the technologically integrated supply chain - they have 11 million types of bicycles). This approach can turn the vicious price spiral into a virtuous loyalty spiral because individualization gives the supplier the opportunity to create a true learning relationship with his client, hereby inducing a growing gap with all his competitors.

\subsection{Supply-chain management}

The mass-customization and especially the mass-individualization is only a feasible strategy for insurers, who are able to manage the supply chain on an integrated basis. This individualization will become feasible, thanks to a total networking between customers and all partners in the supply chain, linked through technology: mass-individualization and

Lannon - 1993. 
supply-chain management make it affordable for the average customer while technology helps to guide them through the labyrinth of choices.

Also the shift form cost-led pricing to price-led costing is only possible if an integrated management of the total cost chain is realized.

This supply-chain management and networking will also make it possible to optimize the combination of many existing management and marketing tools and philosophies, such as TQM ${ }^{2}, \mathrm{BPR}$ and right/down-sizing, outsourcing, core competence, JIT etc.

However, this integrated supply-chain management creates a number of serious threats for companies, working with independent intermediaries, who do not want to enter into a franchise system or a network. It is our firm belief that the tough struggle for independence, which can be especially felt in the market of the smaller brokers and the retail market segments, is a typical marketing paradigm of the past. A tough question brokers and insurers are faced with is where the extra value for the customer is lying : if it is in customization and individualization at an affordable price with a high level of convenience, than integrated supply-chain management is the only solution. Of course such networks need to be shaped in the scope of the democratic corporation and not in the tough "opponents" philosophy of hierarchical structures of the past.

If this modern strategy is followed, the struggle between hybrid marketing channels, which is so typical for the multi-channel approach of insurance nowadays, can disappear : the new challenge is to conceive an integrated distribution strategy (multi-distribution) resulting in a complementary approach that combines the strengths of different distribution formulas.

\subsection{From a closed shop towards networks}

Even big players form alliances. An interesting example in this respect is the Maxis Network, recently set up between two world players, AXA and Metropolitan Life, in order to offer tailored employee benefits to multinational firms, throughout more than 50 countries.

This proves that networking certainly has more to offer than economies of scale. The strength of networks is that they combine the benefits of economies of scale and scope, with the advantages of specialization, flexibility, creativity and enterpreneur-ship.

However, there are no roses without thorns; also networks have disadvantages ${ }^{3}$ : they can create co-ordination problems, it can be harder to reach a consensus and it is often difficult to cooperate with partners who are your competitors in other environments; this co-opetition is attracting a great deal of interest from scientific researchers and consulting goeroes.

${ }^{2}$ Ackoff is rather sceptical about the enthousiasm for TQM. Some of his remarks relate to the fact that improvement programs should be directed at getting what people want, and not at what they do not want; as is usually the case, as Drücker puts it, there is a tremendous difference between doing things right and doing the right things. This means that one should work backwards, from where on wants to be to where one is today and not the other way around as is mostly the case with TQM.

${ }^{3} \mathrm{~A}$ rather critical analysis of the difficulties involved in networking (especially for innovation within high-tech firms) is given by Chesbourgh \& Teece - 1996. 
Although the legal boundaries of corporations remain relevant in certain respects (e.g. for shareholders, creditors, tax authorities and employees), they are losing their significance from a market-economic perspective. Peter Drücker (1995) states that legal entities are fiction from an economic point of view. What matters in the market place is the economic reality, the cost of the entire process, no matter who owns what.

If one opts for the network formula to acquire an international and/or a diversified market position, the question - besides the selection of the right partners - remains how the firm can position itself in each of the networks they are willing to establish or enter into : the position of the leader or major player is tempting, but not realistic for every type of firm or network; one must look for the best exploitation of one's core competences and secure them for the future.

\subsection{Organizing the modern insurance firm}

By meeting these challenges succesfully, firms can create a lasting competitive advantage. This will only be possible if the insurance managers are willing to reshuffle their business organization and unbundle and rebundle the products they offer. The multidimensional organisation - as described by Ackoff - with internal market economies (or profit centres) arranged around the market needs, will be the recipe, rather than the product boxes structure that has guided the insurance organization and product development for decades.

A number of leading global players in other sectors are showing the way : the combined management of the "employee-customer-profit chain" 4 : no profitable business for the shareholder, without delighted customers and satisfied employees; these three stakeholders do not have opposing or conflicting interests, but the ways to fulfill these different interests are rather correlated and complementary.

\section{Creating your own future by reshaping your core business}

\subsection{Create your own future}

The last couple of years, an enormous amount of strategic literature has been published, containing a number of interesting new concepts embedded into the so-called resource-based view, such as core competence ${ }^{5}$, stretch and leverage, etc. Although we do believe that a combination of the well-tried old strategic recipes and these new concepts make the changes of success even more realistic, these new concepts can help to develop a future strategy. 1998.

${ }^{4}$ Most interesting is the one developed by Sears; for further details see Rucci, Kim \& Quinn -

${ }^{5}$ A number of important management experts have made critical remarks on the blind believe in the receipe of core competence. Peter Drücker (1995) points out the fact that this tool is still largely anecdotal. De Geus (1997) is sceptical about the "lasting" competitive advantage, core competence should entail. He suggests to diversify in order to limit the danger of a too concentrated focus on a specific core competence. 
The older strategies remain interesting because they establish the basis for the development of strategic plans. The resource-based view is in our opinion better for the development of the strategic goals and the strategic philosophy. Ambitious firms will indeed feel better with the stretch and leverage concepts than with the limitations of the strategic goals to bridge the gap between ambition and strength and weaknesses, as prescribed by the more classical strategic literature.

We are convinced that the concepts of stretch and leverage are certainly to be taken into consideration when developing the strategic goals for a global or international player in the insurance business.

In short, the essence of the stretch and leverage concept is the following :

- first, determine what your ambition is and set your corporate goals without taking the actual situation into consideration; just let your imagination stretch into ambitious directions;

- analyse the gap between these goals and the actual position, not to decrease your ambition, but to look for ways to be able to realize these ambitions;

- bridge the gap between the actual and the future strategy, preferably by leveraging on the own core competence within diverse networks; if there are not enough financial resources, look for ways to raise capital; if market entry fails, look for acquisition candidates, for merger partners, for network partners or for opportunities to start from scratch, etc...

- in this philosophy the large bulk of funds insurers have to manage, can become an important leverage for expanding the economic role and importance of the insurance corporation; the hot topic of corporate governance has to a large extent been induced by the growing body of active institutional investors; their influence is felt far beyond their own market back yard; their role can only grow as the funds they manage increase and the activism they develop improves their position as well as the society at large.

\subsection{Choosing the right strategic option(s)}

On a product development level, many new options can be envisaged, which entail completely different opportunities and threats :

- all finance, with the emphasis on financial techniques and financial security stresses the role of the institutional investor and that of financial networking and financial conglomerates; this is not only an option for the retail market, with the supply of integrated financial services (emphasing saving, investment and financial security) but also for the corporate market (alternative risk financing techniques and ALM);

- all care with the emphasis on all aspects of risk and security and a supply that goes far be-yond the financial reimbursement; this redirects the focus of attention from the institutional investor towards the management of care and security networks;

- holistic risk management whereby insurance is only one element in the total supply; this reshuffles the role of the insurer form a risk carrier to a risk engineer.

Only some world-wide players will be able to combine all or some of these options; most players will need to make careful choices. 


\subsection{Applying the recipe for success}

The analysis of de Geus (1997) of successful survivors in the business environment world-wide gives an idea of the characteristics of management champions :

- they have a feeling for common values, identity and cohesion;

- they are tolerant in relation to revolutionary ideas and diverging opinions coming from inside and outside the company; survivors have been obliged to review and change their core business drastically several times;

- they possess the learning capacity and are sensitive towards the environment (especially in the developing of strategies); this holds more perspective for future success than the focus on the more static concept of core competence;

- they have a conservative financial management which gives them the necessary flexibility and autonomy;

- they pay attention to all relevant stakeholders; if shareholders focus too much on short term profitability, they can even be a serious hurdle for the development of the living corporation; the importance of the shareholders will decrease in the knowledge society; this evolution will be emphasized by the fact that the legal framework, which gives them control, becomes an anachronism due to the expansion of networks and virtual organizations.

\section{Conclusion}

The insurance sector of the future will bare little resemblance to the one we have observed in the past 50 years. Neither the "bancassurance"- movement, nor the direct selling threats will have the impact that these new developments in strategy, marketing, competition and business organisation will have in the future. The most important observations can be summarized as follows :

- Although there remain some considerable differences between the retail and the industrial insurance market and between the insurance market and the (other) financial sectors, it is clear that the competitive game is evolving from a local over a multinational towards a global competition. However it remains important to distinguish between multinational and global competition; in a multinational competitive environment the multinational suppliers follow the rules of the host country, because of this there is little or no need for a centralised and integrated marketing strategy; a true global competition on the other hand sets new global rules for the competitive game and this leads to a higher degree of co-ordination and interaction between the different companies and subsidiaries within one global group.

Apparently insurance brokers have been taking the lead in this globalization trend, hereby also diversifying into the direction of alternative risk management techniques, alternative risk financing and investment. Only a few insurance companies can really pretend to be already world players. Many options remain open for the bulk of the middle market, but time is pressing.

- A totally new insurance sector with a hyper competitive market environment is emerging as a result of combined effect of revolutionary shifts at both the supply and the 
demand side. The insurable mass and the insurance portfolio are changing drastically, with decreasing emphasis on mature market segments while many new market potential is opening up. Also the risk handling and risk financing techniques show quite impressive innovation routes. At the demand side of the market the knowledge worker is the customer of the future and to understand this new customer the old marketing techniques need to be adapted substantially.

- In the knowledge society of the future the insurance enterprise must be organised as a social system or a living corporation, thus only the new management philosophies will be able to cope with the complex problems of the knowledge society and grasp the opportunities offered.

In order to prosper in this tough and highly demanding market environment, insurers will have to think in radically different paradigms about clients, services and business processes :

- The cost and price strategy will have to change from a cost-led pricing system to a priceled costing.

- The segmentation of client segments, coupled with the extreme tariff differentiation have led to an explosion of the product assortment. Traditional segmentation techniques no longer guarantee success. In order to make the customer happy and to find the right solution for each client in a highly competitive environment the insurer will have to opt for mass-customization and preferably even mass-individualization. This will create a true learning relationship with his client, hereby turning the vicious price spiral into a virtuous loyalty spiral.

- Both previous strategies are only feasible in as far as insurers succeed in managing the total supply chain on an integrated base. For insurers working with independent intermediaries this challenge will be especially tough.

- In such a modern knowledge society, the legal boundaries between companies will be less and less relevant for the customer; the optimal solution will certainly contain one or more network links. Networking certainly has many advantages to offer (besides the benefits of economies of scope and scale, there are advantages of specialization, flexibility, creativity and enterpreneurship). Nevertheless they also offer a number of disadvantages. The great challenge for any insurance company is to find the right partners and to find the best possible position within each of the networks.

- Choosing the right strategic options will be the fundamental key to success. There are many options open : all finance, all care, holistic risk management. In order to make the right choice, the new strategic thinking of stretch and leverage are certainly interesting tools to explore the future of the insurance company. 


\section{REFERENCES}

ACKOFF, R.L. "The Democratic Corporation", Oxford University Press, New York, 1994.

CHESBOURGH, H.W. \& TEECE, D.J.; "When Is Virtual Virtuous? Organizing for Innovation", Harvard Business Review, January-February 1996, pp.65-73.

DE GEUS; "The Living Corporation”, Harvard Business School Press, Boston, 1997.

DRÜCKER, P.; “ Het tijdperk van de sociale transformatie”, Holland Management Review, $\mathrm{N}^{\circ} 42$, 1995.

LANNON, J.; "Consumer megatrends and their implications for the financial industry", Semaine International du Marketing de l'Assurance, CAPA, Paris, 1993, SP2.

LANZA,W.D.; "Risk Securitization Growth Expected", National Underwriter, July 14th, 1997, S-19.

RUCCI, A.J., KIRN, S.P. \& QUINN, R.T.; "The Employee-Customer-Profit Chain at Sears", Harvard Business Review, January-February 1998, pp.83-97.

SIGMA; "Insurance derivatives and securitization : New hedging perspectives for the US catastrophe insurance market?"; Swiss Re, Sigma ${ }^{\circ}$ 5, 1996.

VAN ASSELDONCK, T.; “ Massa-Individualisering : maatwerk zonder meerkosten”, Holland/ Belgium Management Review, $\mathrm{N}^{\circ} 45,1995$, pp. 71-79. 